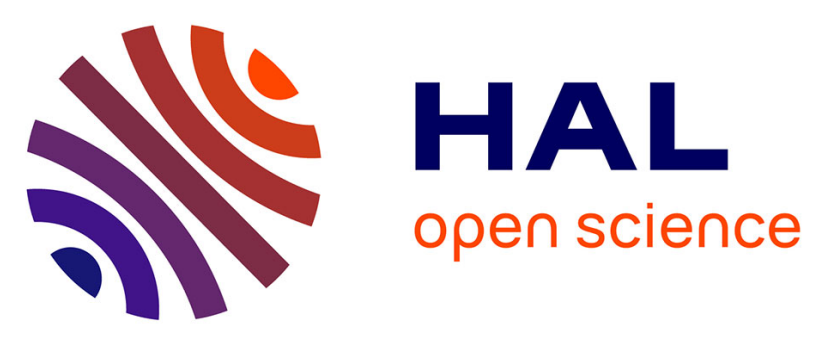

\title{
Very preterm children free of disability or delay at age 2: predictors of schooling at age 8: a population-based longitudinal study.
}

\author{
Marie-Laure Charkaluk, Patrick Truffert, L. Marchand-Martin, S. Mur, \\ Monique Kaminski, Pierre-Yves Ancel, Véronique Pierrat
}

\section{To cite this version:}

Marie-Laure Charkaluk, Patrick Truffert, L. Marchand-Martin, S. Mur, Monique Kaminski, et al.. Very preterm children free of disability or delay at age 2: predictors of schooling at age 8: a population-based longitudinal study.. Early Human Development, 2011, 87 (4), pp.297-302. 10.1016/j.earlhumdev.2011.01.033 . inserm-00581324

\section{HAL Id: inserm-00581324 https://www.hal.inserm.fr/inserm-00581324}

Submitted on 10 Jan 2012

HAL is a multi-disciplinary open access archive for the deposit and dissemination of scientific research documents, whether they are published or not. The documents may come from teaching and research institutions in France or abroad, or from public or private research centers.
L'archive ouverte pluridisciplinaire HAL, est destinée au dépôt et à la diffusion de documents scientifiques de niveau recherche, publiés ou non, émanant des établissements d'enseignement et de recherche français ou étrangers, des laboratoires publics ou privés. 


\section{VERY PRETERM CHILDREN FREE OF DISABILITY OR DELAY AT AGE 2:}

PREDICTORS OF SCHOOLING AT AGE 8.

\section{A POPULATION-BASED LONGITUDINAL STUDY.}

Charkaluk ML ${ }^{1,2,3}$, Truffert $\mathrm{P}^{1,4,5}$, Marchand-Martin L ${ }^{1}$, Mur S ${ }^{4}$, Kaminski M ${ }^{1}$, Ancel PY ${ }^{1,3}$, Pierrat $V^{1,4}$ for the Epipage study group.

1 INSERM, UMR S 953, IFR 69, Research Unit on Perinatal Health and Women's and Children's Health, F-75020,Paris, France.

2 Groupe Hospitalier de l'Institut Catholique Lillois / Faculté Libre de Médecine, F-59000 Lille, France

3 UPMC Univ Paris 06, UMR S 953, F-75005, Paris, France.

4 Service de Médecine Néonatale, Hôpital Jeanne de Flandre, avenue Eugène Avinée, F-59037 Lille cedex, France.

5 Univ Lille Nord de France, F-59000 Lille, France

Keywords: very preterm children, follow-up study, schooling

Abstract word count: 258

Text word count: 3274

Corresponding Author:

M L Charkaluk,

Clinique de Pédiatrie Saint Antoine, Hôpital Saint Vincent de Paul

Boulevard de Belfort

BP 387

59020 Lille cedex

France

email: charkaluk.marie-laure@ghicl.net

tel: 0033320877667

fax: 0033320877668 


\section{ABSTRACT}

Aim: To study the predictive value of a developmental assessment at 2 years corrected age (CA) for schooling at age 8 in children born very preterm and free of disability or delay; to identify other factors associated with schooling in this population.

Methods: 244 children born before 33 weeks in 1997, part of the population-based EPIPAGE cohort study, free from disability or delay, had their developmental quotient (DQ) evaluated with the BrunetLezine scale at 2 years CA. The mental processing composite (MPC) score was evaluated at age 5 with the K-ABC battery. Data on schooling were obtained at age 8 by postal questionnaire. Schooling was considered appropriate if the child was attending age-appropriate grade level in a regular classroom environment without support at school.

Results: Schooling was appropriate for $172(70 \%)$ children. The predictive value of a DQ $\geq 100$ for appropriate schooling was $0.80[0.75 ; 0.85]$. In children with a DQ at age $2<100$, schooling varied significantly according to their MPC score at age 5 whereas it didn't in children with a DQ $\geq 100$. In multivariate analysis, the rate of appropriate schooling was significantly related to global DQ at age 2 $(p<0.01)$, gestational age $\geq 29$ weeks $(p<0.05)$, head circumference at age $2(p<0.05)$ and mother's educational level $(p<0.05)$.

Conclusion: A DQ $\geq 100$ cannot be solely used for the prediction of appropriate schooling at age 8 . Mother's educational level, gestational age and head circumference at age 2 could be taken account. These factors could be used to individualise follow-up. 
A wide range of sequelae can occur after a preterm birth, and both families and neonatal teams are concerned with their early detection [1]. In the first 2 years, follow-up is directed toward the detection of disabilities, particularly in the motor and sensorial domains, and developmental delay [2]. Cognitive functioning is one of the most commonly affected areas of neurodevelopment [3] and can lead to poor academic achievement [4]. School difficulties are also described in preterm children with normal intelligence quotients (IQ), probably because of dysfunctions in areas that are not explored by global cognitive assessments [5], including behavioural problems [6]. According to a recent meta-analysis, the disadvantage in cognitive function, academic achievement, and behavioural problems remains stable during late childhood and persists into early adulthood [6]. A prolonged specific follow-up is therefore recommended [1]. However, follow-up lasting several years cannot be routinely achieved for all very preterm children by most neonatal teams as it is cost and time expensive. This follow-up tends to be stopped at age 1-2 for some children considered to have typical development, but this policy is not evidence-based. Attention is focused on children with impairments, and for children found to be free of severe disability around age 2 , little is known about their cognitive prognosis and the factors affecting it [7].

Longitudinal studies, with successive assessments of neurodevelopment at various ages, are appropriate for studying early predictors of later outcome, but such studies are scarce. Besides, most longitudinal studies are not population-based and can thus be subject to referral bias [7-11]. Many of them included children born before the surfactant era $[8,9,12]$, and inclusion criteria were mainly based on birth weight, except for Australian cohorts [13]. While some authors have found that cognitive performance of extremely low-birth-weight (ELBW) children improved during childhood $[7,10]$, Voss et al found that $15 \%$ of very preterm children considered to be well developed at age 4 were classified as disabled at age 6 [11]. Recently, Roberts et al underlined the poor agreement between disability status at age 2 and 8 for children born at 22-27 weeks of gestation, with some children improving and some worsening [13]. More mature very preterm babies, accounting for the majority of children eligible for systematic developmental follow-up, have not recently been the subject of a longitudinal study. The EPIPAGE study is a French population-based prospective cohort of children born before 33 weeks in 1997. Thus, not only extremely low gestational age children are 
included. In the Nord-Pas de Calais region, one of the nine regions surveyed in the study, a developmental assessment took place at 2 years corrected age (CA) [14]. Children were followed until the age of 8 , which allowed a longitudinal analysis of their development. The main objective of the present study was to assess the predictive value of a psychometric assessment at 2 years CA in very preterm children free of disability or delay at age 2 for schooling at age 8 , particularly the predictive value of a high score at this psychomotor assessment at age 2 for normal schooling at age 8 . A secondary objective was to identify other factors associated with schooling at age 8 among children free of disability or delay at 2 years CA once their psychomotor assessment at 2 years CA was taken into account.

\section{POPULATION AND METHODS}

\section{Study population}

All births between 22 and 32 completed weeks of gestation in all maternity units in the Nord-Pas de Calais region in 1997 were included in the EPIPAGE cohort study. Follow-up involved postal questionnaires and medical and psychometric assessments up to the age of 8 years. Informed consent was obtained from the families of all children participating in the study. The study received the approval of the Commission Nationale de l'Informatique et des Libertés.

\section{Data collection}

Gestational age (GA) refers to completed weeks of amenorrhoea, and the values reported are the best obstetric estimate on the basis of the date of the last menstrual period and an early prenatal ultrasound. The mother's educational level was collected during the neonatal hospitalisation and completed at follow-up when missing. It was classified into three categories: low (elementary school or lower secondary education), intermediate (upper secondary education) or high (university). Paediatricians from the neonatal teams performed a neurological examination as well as an assessment of hearing and vision at 2 years CA [14]. Head circumference was measured and assessed with the World Health Organisation reference curves for corrected age and gender [15]. Cerebral palsy (CP) was defined according to the European Cerebral Palsy Network [16]. The revised Brunet-Lézine 
(BLR) scale was used to assess development [17]. This early childhood psychomotor development scale yields a global developmental quotient (DQ) with a mean of 100 and a standard deviation (SD) of 15 . We were interested in children free of disabilities, i.e. without $\mathrm{CP}$, blindness or requirement of a hearing aid, and free of developmental delay, defined as a global DQ less than 70 in the absence of disability [18].

At age 5, children were invited for a global assessment with a physician and a psychologist [19]. The Kaufman Assessment Battery for Children (K-ABC) was used to assess cognitive function [20]. The mental processing composite (MPC) scale, which is considered to be equivalent to IQ, is a global measure of cognitive ability in two dimensions: a sequential processing scale and a simultaneous processing scale.

When the child was 8 years old, a postal questionnaire was sent to the parents with questions about schooling. Parents were asked in which kind of school and class was their child, and also if their child received a support at school, defined as extra teacher in or outside the classroom, extra teaching hours at the school itself, intervention of a psychologist or another person at school. Schooling was divided into 4 categories: 1. Age-appropriate grade level in a regular classroom environment without support at school; 2. Age-appropriate grade level in a regular classroom environment with support at school; 3 . Regular classroom environment with one grade retained; 4. Specialised school or class. In France, children enter elementary school in September of the civil year of their $6^{\text {th }}$ birthday, whatever GA at birth. If a child is found to have school difficulties, a personalised help can be provided at school, by the teacher him/herself, or a specialised teacher or a psychologist. If these helps are not sufficient, grade retention can be proposed.

\section{Statistical analysis}

Before the analysis, children eligible for the present study at 2 years CA but with missing information on schooling at age 8 were compared to children with information at both ages.

We first studied the relationship between global DQ at age 2 and schooling at age 8. DQ was considered a categorical variable, with 85 (-1 SD) or 100 (mean) as thresholds. Schooling was considered as appropriate if the child was attending age-appropriate grade level without support at 
school. Predictive values of DQ with the different thresholds for appropriate schooling were calculated.

Other factors associated with schooling at age 8 when DQ was taken into account were also studied. As DQ and MPC showed high colinearity, they could not be included in the same model to predict schooling. A stratified analysis was then conducted, comparing the rates of normal schooling at different levels of MPC at age 5 in each category of the DQ. MPC was trichotomised using the mean (106) and - 1 SD (88) of the term-born children in the control group of the EPIPAGE cohort study as thresholds [19]. The chi-square test or Fischer's exact test was used when necessary.

Lastly, we studied the relation between schooling classified in two categories, appropriate or not appropriate, and GA, mother's educational level and head circumference at 2 years CA in univariate analysis (chi-square or Fischer's exact test) and then using a multivariate logistic regression model after adjustment for DQ. These variables were chosen considering the aim of the study. Variables associated with the outcome at $p<0.20$ in the univariate analysis were included in the multivariate model.

STATA, version 9.0, was used to perform univariate and multivariate analyses (Stata Corp, College Station, Texas, USA). A p-value less than 0.05 was considered significant.

\section{RESULTS}

The study population is described in Figure 1. In the Nord-Pas de Calais region, 634 children were born before 33 weeks of gestation in 1997, and 548 survived to discharge. Two were excluded because of congenital abnormalities interfering with neurodevelopment and 461 underwent a medical examination at 2 years CA (84\%). The current study population included the 339 children who underwent a physical examination and a psychometric assessment at age 2 and were considered free of disability or delay. Among these 339 children, data on schooling at age 8 were available for 244 (72\%). The perinatal and sociodemographic data of the study population as well as the characteristics of those lost to follow-up are summarised in Table 1. Children lost to follow-up at age 8 had a higher GA and their mothers had a lower educational level, but the differences were small. 
Children were first assessed at a mean corrected age of $23 \pm 1$ months. Mean DQ was $97 \pm 12$ for the 244 children studied at both ages. DQ was between 70 and 84 in 38 children (16\%), between 85 and 99 in $95(39 \%)$ and 100 or higher in $111(45 \%)$. Data on schooling were collected at a mean age of $107 \pm 4$ months. Overall 172 children were in age-appropriate grade levels in regular classroom environments without support at school (70\%). Twenty were attending age-appropriate grade levels in regular classroom environment with support at school (8\%), 40 were in regular classroom environment having repeated a grade (16\%) and 12 were attending specialised schools or classes $(5 \%)$.

Seventeen very preterm children with a DQ of 70-84 attended appropriate schooling (45\%), 66 of those with a DQ 85-99 (69\%) and 89 of those with a DQ of 100 or higher did so. No child with a DQ of 100 or higher was in specialised school or class. Thus, the predictive value of a DQ $\geq 85$ for attending appropriate schooling was 0.75 (95\% CI: [0.68;0.82)]. The predictive value of a DQ $\geq 100$ for attending appropriate schooling was 0.80 (95\% CI: [0.75;0.85]).

The MPC score was available for 217 children. The analysis of schooling according to assessments at age 2 and age 5 is detailed in Table 2. When DQ at age 2 was between 70 and 84 or 85 and 99, rates of appropriate schooling varied significantly according to their MPC level at age 5. When MPC was $\geq-$ $1 \mathrm{SD}$, even though DQ at age 2 was $<100(n=59)$, schooling was appropriate for 54 children $(92 \%)$. No child with a MPC $\geq 85$ at age 5 was in a specialised school or class, even after having had a DQ equal to 70-99. However, for children with a $D Q \geq 100$ at age 2, no significant relation was found between their MPC level at age 5 and the rate of appropriate schooling at age 8 .

In univariate analysis, schooling at age 8 was associated with GA, mother's educational level and head circumference at age $2(p<0.20)$ (Table 3$)$. All these associations remained significant in multivariate analysis.

\section{DISCUSSION}

This population-based study examined schooling at age 8 of children born very preterm who were free of disability or delay at age 2. Schooling at age 8 was related to the global developmental assessment, 
obtained at age 2 . The predictive value of a DQ $\geq 100$ for an appropriate schooling was $0.80(95 \% \mathrm{CI}$ : $[0.75 ; 0.85])$. This predictive value has to be considered in respect with the finding that $90 \%$ of the term-born children in the control group of the EPIPAGE cohort study have an appropriate schooling at age 8 (data not shown). For very preterm children with a DQ $<100$, schooling at age 8 differed according to MPC category at age 5, and was appropriate in $92 \%$ children with a MPC score $\geq-1$ SD. The association between schooling and GA, head circumference at 2 years CA and mother's educational level remained significant after adjustment for global DQ.

In our study, mean DQ at 2 years CA is higher that what is usually reported, even for the same range of GA [21, 22]. This is explained by the exclusion of children with disability, mainly CP, as gross motor function is part of global DQ [17], and also of children with a DQ $<70$. These exclusions were decided in accordance with the aim of the study, because the questions about the later follow-up for these children are not asked the same way as for children free of disability or delay.

In children born at term, the predictive value of early developmental tests for later intellectual functioning is generally considered poor. However, more than $98 \%$ of children born at term with a global DQ $\geq 85$ achieve an IQ $\geq 85$ [23]. Prediction of later development in children born very preterm is very controversial $[11,24]$. Early prediction of later development is considered to be good for major impairments [24]. Negative predictive values are not always considered useful [7]. When studied, some authors have found psychometric evaluation to have a good negative predictive value $[7,18]$. Other authors studied changes in disability classification between two evaluations and found that the disability status could either improve or deteriorate $[11,13]$. Some children, whose early performance is within the normal range, may not adjust to the increasing demand in cognitive functioning with increasing age $[8,11]$. Others may be able to catch up as early medical complications resolve [10]. This may explain why some authors have described different developmental patterns, which are influenced by biomedical factors as well as maternal education $[9,25]$.

The originality of our study was to focus on individual prediction of normal schooling taking into account not only early global DQ but also other perinatal and sociodemographic factors or data 
available at 2 years CA, an age when it is possible to identify whether or not the child is free of serious disability or delay. In order to ensure a good predictive value for a favourable outcome, the threshold for the global DQ at 2 years CA had to be 100. We found that when the global DQ was less than 100, schooling at age 8 differed in relation to MPC at age 5. While the Brunet-Lezine test positions the child on a global scale evaluating development in four domains (gross and fine motor functions, language and sociability) [17], MPC measures intelligence considered as "a style, peculiar to each individual, characterised by his way of solving problems and treating information" [20]. This is important for parental counselling and substantiates the possible catch-up $[7,10]$.

Social environment is known to be associated with cognitive abilities and schooling in full-term and preterm children $[7,10,20,23]$. Parental education is an important component of social environment and is unlikely to change markedly over time. That is why mother's educational level is widely used in follow-up studies of very preterm children. Many mediators of the social effects on academic achievement have been studied [26]. They include fewer social, educational and material resources which could buffer the negative effects of preterm birth. As well as for term-born children, lack of cognitive stimulation, quality of the child's home environment, interactions between parents and child and parent's status as role models could also be involved [26]. All these factors play a different role at different periods of the child's development. This may explain why the relation between mother's educational level and schooling persists after adjustment for global DQ at 2 years CA, which is already related to social environment [14,22].

Microcephaly at 2 years is known to be associated with poorer cognitive development in preterm children $[27,28]$. In our selected population of children free of disability or delay at 2 years CA, only $7 \%$ of children had a head circumference less than -1 SD at 2 years CA. This low percentage is partly explained by the use of corrected age, in accordance with what was used for psychometric evaluation. Trajectories of head growth could improve model accuracy but were not available in our data set. 
The association between GA and schooling at age 8 remained statistically significant in the multivariate analysis once the global DQ was taken into account. Thus, the role played by a GA $\geq 29$ weeks in appropriate schooling was not entirely explained by overall development at age 2 , because so many more organised skills or appropriate behaviours are needed at school age. One can hypothesize that brain vulnerability is higher before 29 weeks of gestation [29].

Our study has several strengths: it was population-based and thus not subject to referral bias. Not only ELBW or extremely preterm children were included, but all very preterm children. Children studied were born in the surfactant era and can be considered representative of current practices. The question is original, because of its practical clinical perspective: we sought to give paediatricians tools to set up an individual follow-up program for a child free of disability or delay at 2 years CA, according to his or her psychometric evaluation and a few other simple data (GA, mother's educational level, head circumference). For this reason, the analysis was restricted to children free of disability or delay and we focused on the predictive value of a high score.

We are aware of several limitations. Children with missing data at age 8 differed slightly from those included in the study. We had previously shown that children lost to follow-up at age 2 were socially and medically disadvantaged [14]. Thus, our descriptive analysis of cognitive abilities at age 5 and schooling at age 8 is likely to be too optimistic. We might have missed some children with a low DQ and an inappropriate schooling. The predictive value of a low DQ would be biased, but the predictive value of a $D Q \geq 100$ is probably less affected.

The number of events (inappropriate schooling) was a limitation for the number of risk factors we could study. No data about behaviour at age 2 were available, so this factor could not be studied. Schooling is a complex outcome, because it depends on the cognitive abilities of the child but also on behaviour, fine motor skills, visual-spatial integration and executive functions. All these domains may be impaired in preterm children, and this study did not explore them $[4,6]$. Schooling is also a result of the family's resources and motivation to maintain the child in a regular classroom environment, which in some cases makes the interpretation on the relationship between social environment and schooling 
difficult. Lastly, it may depend on the country's education policy, which is a limitation for international comparisons.

We agree that 2 years is not a satisfying end-point for epidemiologic surveys in very preterm children. However, births before 32 weeks account for $0.7-1.4 \%$ of births in Europe [30] and a specific neurodevelopmental follow-up until school age for all these babies cannot be routinely achieved. Our study estimates the predictive value of a psychometric evaluation at 2 years CA for schooling at age 8 . Using GA, head circumference at age 2 and mother's educational level together with global DQ could lead to individualisation of follow-up after 2 years CA, given that time and resources are limited. The appropriate follow-up that could be offered to these children depends on each country's policy for preventive care throughout childhood. Among children with a DQ $<100$ at age 2, an evaluation of cognitive abilities at age 5 is necessary to clarify school outcome. Further studies are needed in order to confirm these findings in a larger group of children. 


\section{ACKNOWLEDGEMENTS}

The authors would like to thank the EPIPAGE Study group in the Nord Pas-de-Calais region:

Artois: A Djebarra, S Lucidarme, C Morisot, S Racoussot.

Lille Métropole: A Bourlet, M Chenaud, S Enchéry, S Rousseau

Littoral: AM Gournay, M Poher, E Robin

Hainaut: G Delebarre, B Pindi, C Zaoui-Grattepanche

\section{CONFLICT OF INTEREST STATEMENT}

The authors declare no financial and personal relationships with other people or organisations that could inappropriately have biased their work.

\section{ROLE OF THE FUNDING SOURCE}

The research was supported by grants from INSERM (National Institute of Health and Medical Research), the Directorate General for Health of the Ministry for Social Affairs, Merck-Sharp and Dohme-Chibret, Medical Research Foundation and the Hospital Program for Clinical Research of the French Department of Health. The sponsors had no role in the study design, the collection, analysis and interpretation of data, in the writing of the manuscript and in the decision to submit the manuscript for publication. 


\section{REFERENCES}

1. Dorling JS, Field DJ. Follow up of infants following discharge from the neonatal unit: structure and process. Early Hum Dev 2006;82(3):151-6.

2. Msall ME. Neurodevelopmental surveillance in the first 2 years after extremely preterm birth: Evidence, challenges, and guidelines. Early Hum Dev 2006;82(3):157-66.

3. Saigal S, Doyle LW. An overview of mortality and sequelae of preterm birth from infancy to adulthood. Lancet 2008;371(9608):261-69.

4. Anderson PJ, Doyle LW. Cognitive and educational deficits in children born extremely preterm. Semin Perinatol 2008;32(1):51-8.

5. Aylward GP. Cognitive and neuropsychological outcomes: more than IQ scores. Ment Retard Dev Disabil Res Rev 2002;8(4):234-40.

6. Aarnoudse-Moens CS, Weisglas-Kuperus N, van Goudoever JB, Oosterlaan J. Meta-analysis of neurobehavioral outcomes in very preterm and/or very low birth weight children. Pediatrics 2009;124(2):717-28.

7. Hack M, Taylor HG, Drotar D, Schluchter M, Cartar L, Wilson-Costello D, et al. Poor predictive validity of the Bayley Scales of Infant Development for cognitive function of extremely low birth weight children at school age. Pediatrics 2005;116(2):333-41.

8. Roth SC, Baudin J, Pezzani-Goldsmith M, Townsend J, Reynolds EO, Stewart AL. Relation between neurodevelopmental status of very preterm infants at one and eight years. Dev Med Child Neurol 1994;36(12):1049-62.

9. Koller H, Lawson K, Rose SA, Wallace I, McCarton C. Patterns of cognitive development in very low birth weight children during the first six years of life. Pediatrics 1997;99(3):383-9.

10. Ment LR, Vohr B, Allan W, Katz KH, Schneider KC, Westerveld M, et al. Change in cognitive function over time in very low-birth-weight infants. JAMA 2003;289(6):705-11.

11. Voss W, Neubauer AP, Wachtendorf M, Verhey JF, Kattner E. Neurodevelopmental outcome in extremely low birth weight infants: what is the minimum age for reliable developmental prognosis? Acta Paediatr 2007;96(3):342-7. 
12. Weisglas-Kuperus N, Baerts W, Smrkovsky M, Sauer PJ. Effects of biological and social factors on the cognitive development of very low birth weight children. Pediatrics 1993;92(5):658-65. 13. Roberts G, Anderson PJ, Doyle LW. The stability of the diagnosis of developmental disability between age 2 and 8 in a geographic cohort of very preterm children born in 1997. Arch Dis Child 2010;95(10):786-90.

14. Charkaluk ML, Truffert P, Fily A, Ancel P, Pierrat V, Epipage study group. Neurodevelopment of children born very preterm and free of severe disabilities: the Nord-Pas de Calais Epipage cohort study. Acta Paediatr 2010;99(5):684-9.

15. Child growth standards. Head circumference-for-age tables. http://who.int/childgrowth/standards/hc_for_age/en/index.html. Assessed 10 jan 2011.

16. Surveillance of cerebral palsy in Europe. Surveillance of cerebral palsy in Europe: a collaboration of cerebral palsy surveys and registers. Surveillance of Cerebral Palsy in Europe (SCPE). Dev Med Child Neurol 2000;42(12):816-24.

17. Josse D. Brunet-Lezine révisé : Echelle de développement psychomoteur de la première enfance. Paris, France: Etablissements d'applications psychotechniques; 1997.

18. Patrianakos-Hoobler AI, Msall ME, Huo D, Marks JD, Plesha-Troyke S, Schreiber MD. Predicting school readiness from neurodevelopmental assessments at age 2 years after respiratory distress syndrome in infants born preterm. Dev Med Child Neurol 2010;52(4):379-85.

19. Larroque B, Ancel P, Marret S, Marchand L, André M, Arnaud C, et al. Neurodevelopmental disabilities and special care for 5-year-old children born before 33 weeks of gestation (the EPIPAGE study): a longitudinal cohort study. Lancet 2008;371(9615):813-20.

20. Kaufman A, Kaufman N. Kaufman assessment battery for children. Minnesota: Circle Pines; 1983.

21. Stoelhorst GM, Rijken M, Martens SE, van Zwieten PH, Feenstra J, Zwinderman AH, et al. Developmental outcome et 18 and 24 months of age in very preterm children: a cohort study from 1996 to 1997. Early Hum Dev 2003;72(2):83-95. 
22. Fily A, Pierrat V, Delporte V, Bréart G, Truffert P, EPIPAGE Nord-Pas de Calais Study Group. Factors associated with neurodevelopmental outcome at two years after preterm birth: The population based Nord-Pas-de-Calais EPIPAGE cohort. Pediatrics 2006;117(2):357-66.

23. Largo R, Graf S, Kundu S, Hunziker U, Molinari L. Predicting developmental outcome at school age from infant tests of normal, at risk and retarded infants. Dev Med Child Neurol 1990;32(1):30-45.

24. Latal B. Prediction of neurodevelopmental outcome after preterm birth. Pediatr Neurol 2009;40(6):413-9.

25. Wang LW, Wang ST, Huang CC. Preterm infants of educated mothers have better outcome. Acta Paediatr 2008;97(5):568-73.

26. McLoyd VC. Socioeconomic disadvantage and child development. Am Psychol 1998;53(2):185-204.

27. Cheong JL, Hunt RW, Anderson PJ, Howard K, Thompson DK, Wang HX, et al. Head growth in preterm infants: correlation with magnetic resonance imaging and neurodevelopmental outcome. Pediatrics 2008;121(6):e1534-40.

28. Kuban KC, Allred EN, O'Shea TM, Paneth N, Westra S, Miller C, et al. Developmental correlates of head circumference at birth and two years in a cohort of extremely low gestational age newborns. J Pediatr 2009;155(3):344-9.

29. Ment LR, Hirtz D, PS Hüppi. Imaging biomarkers of outcome in the developing preterm brain. Lancet Neurol 2009;8:1042-55.

30. Euro PERISTAT Project, with SCPE, EUROCAT, EURONEOSTAT. European perinatal health report. 2008. http://europeristat.com/bm.doc/european-perinatal-health-report.pdf. Assessed 10 jan 2011. 